\title{
Developing Psychological Well-Being Scale for Preschool Children
}

\author{
Nazanin Abed ${ }^{1}$, Shahla Pakdaman ${ }^{1}$, Mahmood Heidari ${ }^{1} \&$ Karineh Tahmassian $^{2}$ \\ ${ }^{1}$ Department of Psychology, Shahid Beheshti University of Tehran, Iran \\ ${ }^{2}$ Family Research Institude, Shahid Beheshti University of Tehran, Iran \\ Correspondence: Nazanin Abed, Department of Psychology, Shahid Beheshti University of Tehran, Iran. E-mail: \\ nazanin.abed3@gmail.com
}

Received: November 23, 2015 Accepted: January 25, 2016 Online Published: February 29, 2016

doi:10.5539/gjhs.v8n11p104 URL: http://dx.doi.org/10.5539/gjhs.v8n11p104

\begin{abstract}
The aim of this research was to develop a scale in order to measure psychological well-being in preschool children. Three hundred and seventy five to six year old children participated in the research from 5 regions of Tehran, using accidental sampling method. The participants were individually interviewed with the Well-Being in Preschool Children Scale, and their teachers completed Rutter's Child Behavior Questionnaire about each of them. Data was analyzed with both exploratory and confirmatory factor analysis methods using WLSMV and GEOMIN oblique rotation, to examine factorial structure. Samejima's graded response model was used to access psychometric features of the items. Test-retest reliability was measured and Pearson's correlation was also used to assess divergent and convergent validity. Findings revealed that this scale has 3 main factors: self-concept, life satisfaction and resilience. The validity and reliability of the scale is also satisfactory. The well-being indicators in this scale are consistent with previous research on components of well-being in children. In addition there is a negative correlation between psychological well-being and behavioral problems, which is also illustrated in previous research.
\end{abstract}

Keywords: children, life satisfaction, psychological well-being, resilience, scale, self-concept

\section{Introduction}

Childhood remains a crucial period for shaping mental structure of individuals, and its affects remain in all aspects of life. Researchers have studied and explored many factors in shaping this structure. One of them is psychological well-being. Quantitatively it has been found that high scores of psychological well-being increase positive aspects of mental health in children, such as self-confidence, self-esteem and social-emotional development (Dwivdi \& Bringley Harper, 2004). During past decades concerns about children's well-being and quality of life of children has also increased. Although researchers and policy makers have been working on child safety and mental health of children for many years, child well-being appears to be a much more complex concept to define and measure (Jones, Laliberte, \& Piescher, 2015). The importance of the issue is as much as The United Nations children's Fund (UNICEF) has a report card evaluating children's overall well-being in 29 developed countries and ranked the countries accordingly. The overall well-being in this report card has five dimensions: material well-being, health and safety, education, behaviors and risks and housing and environment (Unicef, 2013). Afterwards many research has been conducted in order to define well-being, explore its indicators and estimate the effect of different states of psychological well-being in individuals' lives. Developed societies and their policy makers are also allocating budget and concern on enhancing psychological well-being in children.

Psychological well-being refers to any positive state that contains mental, psychological and emotional aspects of individual's life and results in flourishing and thriving (Linley \& Joseph, 2004). Psychological well-being also refers to people's psychological performance, life satisfaction and the ability to develop and maintain positive interpersonal relationships. It is also the ability of experiencing autonomy, self-acceptance and personal growth and is correlated with factors such as self-esteem, self-concept and self-confidence. An important fact to keep in mind is that psychological well-being is different from mental health. Because psychological well-being refers to positive states of being, behaving and feeling but mental health refers to a range of psychological problems that one can experience from very good mental health to severe mental health problems (Exenberger \& Juen, 2014; Putz, O’Hara, Taggart, \& Stewart-Brown, 2012; Stewart-Brown \& Janmohamed, 2008). White (1994) also 
believes that the feeling or belief that people have about themselves or the world around them comes from the state of their psychological well-being. Psychological well-being is a general state of "feeling good" or "feeling bad" (White, 1994). Ryff (1995) also presented a theoretical model of psychological well-being that contains 6 distinct dimensions of well-being: autonomy, personal growth, environmental mastery, positive relations with others, purpose in life and self-acceptance (Ryff, 1995).

Well-being is clearly a complex construct that concerns optimal experience and functioning. Research on well-being has been derived from two general perspectives: the hedonic approach and the eudaimonic approach. The first approach focuses on happiness and defines well-being in terms of achieving pleasure and avoiding pain. The eudaimonic approach focuses on meaning and purpose of life and self-realization, and defines well-being in terms of the degree that a person is fully functioning (Ryan \& Deci, 2001).

Psychological well-being is used and specially defined for children as well; the national health system of England believes that children who experience higher states of psychological well-being have the following abilities:

- develop psychologically, emotionally, creatively, intellectually and spiritually

- $\quad$ initiate, develop and sustain mutually satisfying personal relationships

- $\quad$ use and enjoy solitude

- $\quad$ become aware of others and empathize with them

- play and learn

- develop a sense of right and wrong

- face problems and setbacks and learn from them, in ways appropriate for that child's age (Dwivedi \& Brinley Harper, 2004).

Also UNICEF considers some criteria for children as initial indicators of their well-being, such as children's health, safety, education and socialization, their feeling about being valuable and loveable in the family and society, participating in decisions that involve themselves, being respected and listened to (McAuley \& Rose, 2010).

Psychological well-being has negative indicators as well; behaviors or mental states that are negatively correlated with this concept, including aggression, antisocial behaviors, depression and maladaptation.

Gutman and Feinstein (2008) have studied the negative indicators for psychological well-being and mental health. They believe aggression (physical or verbal) and antisocial behaviors such as peer bullying and victimization, are negatively correlated with psychological well-being. Their study illustrates that different forms of antisocial behaviors in children are associated with each other, and lower levels of well-being. Surprisingly most of the negative indicators for psychological well-being are related to each other and to positive aspects of mental health: antisocial behaviors are positively related to maladaptive behaviors and negatively related to adjustment. It means that victims of peers aggression or aggressive children, experience depression and have lower self-esteem. Depression in children is also related to poor functioning, interpersonal and behavioral problems and eventually lower psychological well-being (Gutman \& Feinstein, 2008). Dwivedi and Brinley Harper (2004) in their book about well-being in children explain that higher rates of emotional and behavioral problems in preschool children (such as sleeping disturbance, feeding problems, anxiety, aggression, hyperactivity and etc.) are correlated with lower levels of well-being (Dwivedi \& Brinley Harper, 2004). The relationship between life satisfaction and violent and aggressive behaviors in adolescents was also demonstrated in a survey. This study illustrated that carrying a weapon, physical fighting, being injured and stealing are associated with reduced life satisfaction in adolescents (Valois, Zullig, Huebner, \& Drane, 2001).

\subsection{Theoretical Background}

There are many approaches discussing the importance of child well-being in his own life and in the whole society. A few of them will briefly be reviewed here.

The ecological approach to child's well-being was developed by Bronfenbrenner in 1970s suggesting that all the experiences that children have will contribute to their overall well-being. According to this theory children are surrounded by layers of social groups such as family, peers, school, neighborhood and the whole society which they all have an influence on the child (Bronfenbrenner, 1986). According to ecological approach the environment has different structures as following; microsystem, containing social roles and interpersonal relationships that an individual experiences. Mesosystems are the linkage and processes between two or more 
settings that surround the individual. Exosystem is the linkage between two or more settings that at least one of them does not directly surround the individual, but indirectly influences him. Macrosystem contains beliefs, knowledge, life styles and culture. Chronosystem extends the environment to a third dimension and contains change or consistency over time, in the characteristics of the individual and his environment (Bronfenbrenner, 1994). Since the characteristics of these settings are different for each individual, every child has unique experiences that are influenced by his/her environment. The influence of ecological system on each child's feelings and experiences is one of the reasons that no one can report child's well-being state better than him/herself.

Developmental psychologists completed the ecological approach by linking child well-being to the concept of wellness. According to this approach child wellness is predicated on the satisfaction of physical, mental, affective and psychological needs. Wellness is an ecological concept that can be influenced by the level of parental, familial, and social wellness (Prilleltensky \& Nelson, 2000). A strengths approach to well-being is a more optimistic approach to children, believing in the importance of children's strengths and achievements. It suggests that psychologists should emphasize on positive qualities, personal effectiveness and well-being rather than individuals' anxieties and deficits (Schaffer, 1996). Schaffer believes that children can change; they can recover from negative experiences such as adversity, separation, rejection and loss, and have subsequent experiences that help them build their resilience (Schaffer, 1996).

A child-centered approach of Ben-Arieh has also highlighted the fact that there should be a re-definition of child well-being with two underlying assumptions: that children are entitled to dignity and basic human rights, and childhood is also a stage deserving attention and respect. He also argues that children's own perspectives on their well-being should be considered in order to measure this concept and plan strategies to enhance it (Ben-Arieh, 2005).

It can be argued that psychological well-being measurements that collect data from parents and teachers are not as reliable as children's reports about themselves, because psychological well-being is about the individual's views about his/her personal feelings and relationships (Ben-Arieh, 2005; Mc Auley \& Rose, 2010). Therefore different scales were developed in order to collect data from children. One of them is 'Tellus' survey launched by Ofsted as an online survey in 2007, which gathers the views of children and young people in Years 7,8 and 10, on their life, their school and their local area. This survey had 5 questions about happiness, relationships with friends and family (Chamberlain, George, Golden, Walker, \& Benton, 2010). Another scale was the British Household Panel youth questionnaire that has asked 11-15 year-olds about three dimensions: happiness (about family, friends, overall satisfaction, school), feeling troubled (sadness, worried, depressed) and self-esteem (being a likeable person, feeling useful) since 1994 (McAuley \& Rose, 2010). The Health Behavior of School-Aged Children (HBSC) is another survey based on a school-based sample of 11, 13 and 15 year-olds undertaken every four years (the most recent being in 2005-6). There are a number of questions in this scale that cover subjective well-being in these domains: life satisfaction, liking school, quality of family relationships, peer relationships (Bradshaw \& Richardson, 2009). In addition "the Stirling children's well-being scale (SCWBS) was developed to measure emotional and psychological well-being in children aged 8 to 15 . The indicators were: optimism, cheerfulness and relaxation; satisfying interpersonal relationships; clear thinking and competence. SCWBS is a single dimensioned scale with two sub-components and research shows its reliability and validity (Godfrey, Devine-Wright, \& Taylor, 2015). Another research on conceptualizing children's well-being using data from interviewing 8-17 year old children, their parents and teachers concluded that main factors for children's well-being are positive affect, life satisfaction and meaning in life (Ravens-Siebere et al., 2014).

With the above background context in mind, it can be argued that all the scales that measure psychological well-being in children collect data from 7 year-olds and older. It this research a scale is developed in order to measure the psychological well-being in 5 and 6 year old children. The components of this scale are selected according to the previous theories and scales that have clarified well-being indicators for children and some of them were described above (such as Thompson \& Aked, 2009; Godfrey, Devine-Wright \& Taylor, 2015; Bradshaw \& Richardson, 2009; McAuley \& Rose, 2010; Chamberlain, George, Golden, Walker, \& Benton, 2010 and etc.). Therefore the components are: Self-concept, Relationship with friends, relationship with family, satisfaction of school, resilience, happiness, and life satisfaction.

\section{Method}

\subsection{Participants}

Three hundred and seventy five to six year old children from Tehran participated in this study. In order to control the influence of socioeconomic level of children in the survey, data was selected using accidental sampling 
method, from both public and private settings in five regions in Tehran: north, south, east, west and center, which are socioeconomically different. All participants were interviewed with the Well-Being in Preschool Children Scale. Rutter's child behavior questionnaire was also completed for each child by their respective teacher. The mean for children's age was $5.58(\mathrm{SD}=.493) .151$ participants were girls $(40.8 \%)$ and $219(59.2 \%)$ were boys. Also 106 (28.6\%) participants were from north, 52 (14.1\%) from south, $83(22.4 \%)$ from east, $79(21.4 \%)$ from west and $50(13.5 \%)$ from center of Tehran.

\subsection{Scales}

\subsubsection{Well-Being in Preschool Children Scale}

Indicators of this scale were extracted from different theories and scales about psychological well-being overall and in children. Accordingly this questionnaire covered these areas in psychological well-being: self-concept, satisfaction with peer relationships, satisfaction with family relationships, life satisfaction overall and resilience. Answers were: "yes", "no" and "sometimes".

\subsubsection{Rutter Child Behavior Questionnaire}

This questionnaire was developed by Rutter in 1967. It has two forms: A for parents with 31 questions and B for teachers with 26 questions. Good retest and inter-rated reliability were demonstrated by Rutter (Rutter, 1967). It is an effective scale for screening children with behavioral problems. The scale's validity and reliability was also tested in Iran and the Iranian research explored 5 factors for this questionnaire: 1. Aggression, 2. Anxiety and depression, 3. Social maladjustment, 4. Antisocial behaviors, 5. Attention deficit hyperactivity disorder (Mehryar $\&$ Yousefi, 2010).

\subsection{Data Analysis}

Data was analyzed using SPSS 21, MPlus and Amos. Both exploratory and confirmatory factor analysis were used to examine factorial structure; test-retest analysis for reliability of the questionnaire, and correlation for assessing divergent and convergent validity of the questionnaire.

\section{Results}

Exploratory and confirmatory factor analysis methods were used to examine factorial structure. To explore underlying factors of psychological well-being, WLSMV and GEOMIN oblique rotation were used. Fitness statistics provided by Mplus shows that models with one or two factors have lower fitness statistics than standard, but model with three factors has proper values of fitness (Table 1).

Table 1. Fitness statistics of one, two, three and four-factor models for children's psychological well-being scale

\begin{tabular}{llll}
\hline Model & Approved values & Observed values & Fitness statistics \\
\hline 1 factor & .90 & .75 & CFI \\
& .90 & .74 & GFI \\
& .08 & .117 & RMSEA \\
\hline 2 factors & .90 & .86 & CFI \\
& .90 & .85 & GFI \\
& .08 & .091 & RMSEA \\
\hline 3 factors & .90 & .95 & CFI \\
& .90 & .94 & GFI \\
& .08 & .057 & RMSEA \\
\hline
\end{tabular}

Findings reveal that a three-factor model is fit. Then, using confirmatory factor analysis method for another 200 participants, cross-validation was conducted. Based on the result of exploratory factor analysis, the model in Figure 1 was developed. 


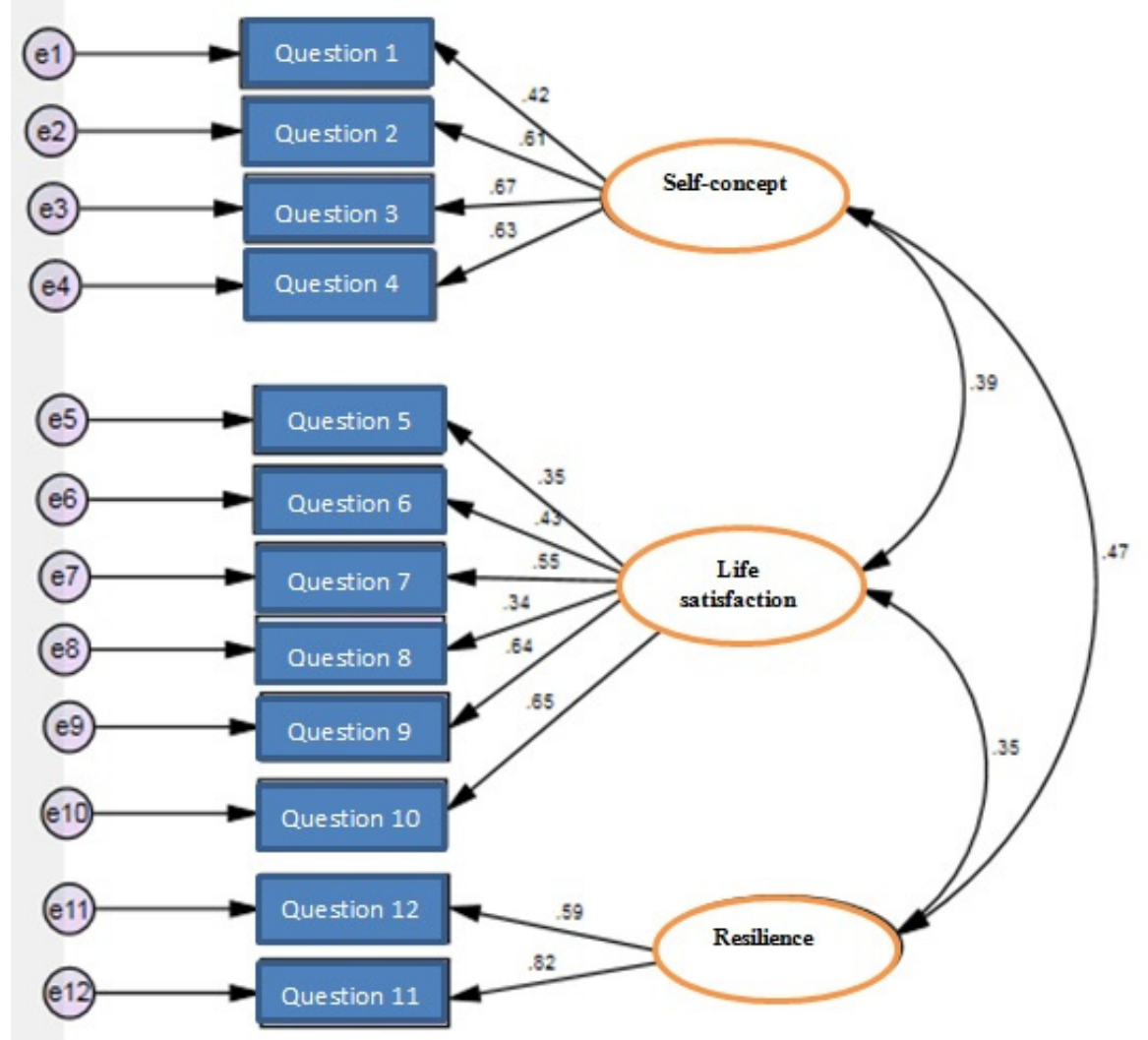

Figure 1. three-factor model based on EFA

Table 2. Fitness statistics of a three-factor model in Well-Being in Preschool Children Scale

\begin{tabular}{llll}
\hline Model & Fitness statistics & Observed values & Approved values \\
\hline 3 factor & CFI & .882 & .90 \\
& GFI & .923 & .90 \\
& RMSEA & .06 & .08 \\
\hline
\end{tabular}

Samejima's graded response model was also applied in order to examine psychometric features. Because there were three main factors for the scale, uni-dimensional item response model was conducted separately for items related to each factor. According to fitness statistics, all items of the model have proper fitness.

Table 3. Parameter estimation of Well-Being in Preschool Children Scale using Samejima's graded response model

\begin{tabular}{lccc}
\hline Items & $\boldsymbol{c}_{\mathbf{2}}$ & $\boldsymbol{c}_{\mathbf{1}}$ & $\boldsymbol{A}$ \\
\hline I like my self & 1.46 & 4.22 & 1.30 \\
I am likeable & .99 & 4.32 & 2.13 \\
My friends like me & .90 & 4.07 & 1.64 \\
I am happy when I am with my friends & 1.68 & 3.76 & 1.52 \\
My family like me & 2.13 & 5.61 & 1.03 \\
I am happy when I am with my family & 2.29 & 4.82 & 1.63 \\
I am a happy person & 1.63 & 5.62 & 1.60 \\
\hline
\end{tabular}




\begin{tabular}{|c|c|c|c|}
\hline I am important for my parents & 1.99 & 4.20 & 1.45 \\
\hline I have a good life and I am happy with it & 2.49 & 5.94 & 2.58 \\
\hline Which one of these faces are you most of the time & 1.14 & 5.63 & 1.60 \\
\hline $\begin{array}{l}\text { When a problem happens to me, for example my favorite toy breaks, I } \\
\text { calm down soon }\end{array}$ & .16 & 1.89 & 1.57 \\
\hline When a problem happens to me, I can solve it & 2.12 & 10.28 & 9.20 \\
\hline
\end{tabular}

Regarding results, all slope and difficulty coefficients of items were proper psychometrically. Slopes of all items were not negative or lower than 1 . Difficulty coefficients of all items were positive as well.

In order to examine reliability of the scale test-retest reliability was used (Table 4). Test-retest reliability coefficients of the scale dimensions show high levels of reliability.

Table 4. Test-retest reliability of the scale

\begin{tabular}{ll}
\hline Factor & Test-Retest Reliability $\left(\mathbf{R}^{\mathbf{2}}\right)$ \\
\hline Self-concept & 799. \\
Life satisfaction & 845. \\
Resilience & 76. \\
\hline
\end{tabular}

The correlations between dimensions of psychological well-being and Rutter's Child Behavior Questionnaire were assessed to examine divergent and convergent validity. Regarding inverse correlations between dimensions of psychological well-being and dimensions of Rutter's Chid Behavior Questionnaire, and direct relationship between dimensions of children's psychological well-being, this scale has proper divergent and convergent validity.

Table 5. Pearson's correlation coefficients between Well-Being in Preschool Children Scale and Rutter's Child Behavior Questionnaire

\begin{tabular}{|c|c|c|c|c|c|c|c|c|}
\hline & 1 & 2 & 3 & 4 & 5 & 6 & 7 & 8 \\
\hline 1. & aggression and hyperactivity & 1 & & & & & & \\
\hline 2. & anxiety and depression & $.389 * *$ & 1 & & & & & \\
\hline 3. & social maladjustment & $.756^{* *}$ & $.249 * *$ & 1 & & & & \\
\hline 4. & antisocial behaviors & $.618^{* *}$ & $.474 * *$ & $.568 * *$ & 1 & & & \\
\hline 5. & ADHD & $.814^{* *}$ & $.206^{* *}$ & $.939 * *$ & $.467 * *$ & 1 & & \\
\hline 6. self-concept & $-.283 * *$ & $-.174 *$ & $-.236 * *$ & $-.255^{* *}$ & $-.201 * *$ & 1 & & \\
\hline 7. life satisfaction & -.071 & .025 & .022 & -.057 & -.012 & $.227 * *$ & 1 & \\
\hline 8. resilience & $-.222 * *$ & -.019 & $-.240 * *$ & -.033 & $-.270 * *$ & $.260 * *$ & $.208 * *$ & 1 \\
\hline
\end{tabular}

\section{Discussion}

This study was conducted to develop a scale for measuring psychological well-being in preschool children. Data analysis found 3 main factors for the scale: self-concept, life satisfaction and resilience. Findings revealed that the Well-Being in Preschool Children Scale is a valid and reliable scale for measuring well-being in preschool children.

Well-being indicators in this study are consistent with previous studies and theories about components of psychological well-being in children (Godfrey, Deine-Wright, \& Taylor, 2015; Ravens-Sieberer et al., 2014; Chamberlain et al., 2010; Mc Auley \& Rose, 2010; Bradshaw \& Richardson, 2009; Prilleltensky \& Nelson, 2000; Ryff, 1995; Bronfenbrenner, 1986). "Tellus" project found happiness, relationship with friends and family to be the main indicators for 7 to 10 year old children's well-being (Chamberlin et al., 2010). British Household Panel 
Youth questionnaire also found three dimensions for well-being in 11 to 15 year-olds: happiness (about family, friends, overall satisfaction and school), feeling troubled (sadness, worried and depressed) and self-esteem (McAuley \& Rose, 2010). The health behavior of school children is another scale for 11 to 15 year-olds considering well-being indicators for children to be life satisfaction, liking school, quality of family relationships and peer relationships (Bradshaw \& Richardson, 2009). Stirling children's well-being scale for 8-15 years old children counts similar indicators for well-being in children (Godfrey, Devine-Wright, \& Taylor, 2015). An interview-based research on conceptualizing well-being in children found positive affect, life satisfaction and meaning in life as main indicators for well-being as well (Ravens-Siebere et al., 2014).

As clarified in previous research, there is a negative correlation between psychological well-being and behavioral and mental problems (Valois, Zullig, Huebner, \& Drane, 2001; Dwivedi \& Brinley Harper, 2004; Gutman \& Feinstein, 2008); Physical or verbal aggression, maladaptive behaviors and antisocial behaviors are negatively correlated with psychological well-being (Gutman \& Feinstein, 2008), emotional and behavioral problems in preschool children are also negatively correlated with psychological well-being (Dwivedi \& Brinley Harper, 2004) and higher rates of violent and aggressive behaviors are correlated with lower rates of life satisfaction (Valois, Zullig, Huebner, \& Drane, 2001). This relationship was revealed in the current study considering the negative correlation between Well-Being in Preschool Children Scale and Rutter's Child Behavior Questionnaire.

The comments made by children in the study lend more details to the survey. They all reported that they understand every question and they could explain the meaning of each question with examples. Most of the children added details and examples to questions number 11 and 12 (resilience factor) from their everyday experiences. Almost all of the children explained "likeable" according to their perceived popularity. Shy children did not have problems answering the questions and this can be a strength of this scale. Some children found the interview very interesting and asked the interviewers to do this again.

This research was conducted on a sample from Tehran, but the evaluation could be stronger if data was collected from different cities in Iran. Evaluation would also be stronger if parents' and teachers' reports about children's well-being could corroborate self-reports from children.

In addition while the items of the Well-Being in Preschool Children Scale are not culture-depended or language-depended, and also the well-being components in this questionnaire are extracted from international theories and questionnaires in this area, collecting data from different countries and cultures may be of interest. Further study can also focus on gender differences in psychological well-being and its components.

\section{Conflict of Interest}

The authors declare that there is no conflict of interests regarding the publication of this paper.

\section{References}

Ben-Arieh, A. (2005). Where are the children? Children's role in measuring and monitoring their well-being. Social Indicators Research. 74, 573-596. http://dx.doi.org/10.1007/s11205-004-4645-6

Bradshaw, J., \& Richardson, D. (2009). An index of child well-being in Europe. Child Ind Res. http://dx.doi.org/10.1007/s12187-009-9037-7

Bronfenbrenner, U. (1986). Ecology of the family as a context for human development: Research perspectives. Developmental Psychology, 22(6), 723-742. http://dx.doi.org/10.1037/0012-1649.22.6.723

Bronfenbrenner, U. (1994). Ecological models of human development. International Encyclopedia of Education. Vol 3, $2^{\text {nd }}$ Ed, 37-43.

Chamberlain, T., George, N., Golden, S., Walker, F., \& Benton, T. (2010). Tellus4 national report. National $\begin{array}{lllll}\text { foundation } & \text { for } & \text { educational } & \text { research. }\end{array}$ http://collectionsr.europarchive.org/tna/20111108225525/

Dwivedi, K. N., \& Brinley Harper, P. (2004). Promoting the emotional well-being of children and adolescents and preventing their mental ill health. London: Jessica Kingsley Publishers.

Exenberger, S., \& Juen, B. (2014). Well-being, resilience and quality of life from children's perspective. Springer Briefs in well-being and quality of life research. http://dx.doi.org/10.1007/978-94-007-7519-0_1

Godfrey, C., Devine-Wright, H., \& Taylor, J. (2015). The positive impact of structured surfing courses on the well-being of vulnerable young people. Community Practitioner, 88(1), 26-29.

Gutman, L. M., \& Feinstein, L. (2008). Children's well-being in primary school: pupil and school effects. 
London: centre of research on the wider benefits of learning.

Jones, A. S., Laliberte, T., \& Piescher, K. N. (2015). Defining and strengthening child well-being in child protection. Child and Youth Services Review, 54, 57-70. http://dx.doi.org/10.1016/j.childyouth.2015.05.001

Linley, P. A., \& Joseph, S. (2004). Positive Psychology in practice. New Jersey: John Wiley and Sons, Inc.

McAuley, C., \& Rose, W. (2010). Child well-being: understanding children's lives. London: Jessica Kingsley Publishers.

Mehryar, A. H., \& Yousefi, F. (2010). Factor structure of Rutter's child behavior scale for completion by teachers in Iran. Tehran: Azmon Yar Pouya Ins.

Prilleltensky, I., \& Nelson, G. (2000). Promoting child and family well-ness: Priorities for psychological and social interventions. Journal of Community and Applied Social Psychology. 3, $2^{\text {nd }}$ Ed, 37-43.

Putz, R., O'Hara, K., Taggart, F., \& Stewart-Brown, S. (2012). Using WEMWBS to measure the impact of your work on mental well-being: a practice-based user guide. Well-being project. Coventry: Coventry city council.

Ryan, R. M., \& Deci, E. L. (2001). On happiness and human potentials: A review of research on hedonic and eudaimonic well-being. Annual Review Psychology, 52, 141-166. http://dx.doi.org/10.1146/annurev.psych.52.1.141

Ryff, C. D. (1995). Psychological well-being in adult life. Current Directions of Psychological Science, 4(4), 99-104. http://dx.doi.org/10.1111/1467-8721.ep10772395

Schaffer, H. R. (1996). Social Development. Cited in A. S. Masten \& D. Coatsworth, The development of competence in favorable and unfavorable environments. American Psychologist, 53(2), 205-220. Retrieved from http://www.researchgate.net/0deec517a89cb33257000000

Stewart-Brown, S., \& Janmohamed, K. (2008). Warwick-Edinburgh mental well-being scale: User guide. London: NHS Publications.

Thompson, S., \& Aked, J. (2009). A guide to measuring children's well-being. London: New Economics Foundation (nef).

UNICEF Innocenti Research Centre. (2013). An overview of child well-being in rich countries. Florence: UNICEF.

Valois, R., Zullig, K., Huebner, S., \& Drane, W. (2001). Relationhip between life satisfaction and violent behavior among adolescents. American Journal of Health Behavior. http://dx.doi.org/10.5993/AJHB.25.4.1

White, T. (1994). Life positions. Transactional Analysis Journal, 24(4), 269-276.

\section{Copyrights}

Copyright for this article is retained by the author(s), with first publication rights granted to the journal.

This is an open-access article distributed under the terms and conditions of the Creative Commons Attribution license (http://creativecommons.org/licenses/by/3.0/). 